\title{
EFFECTIVE TEACHING ELEMENTS IN ONLINE ADULT LEARNING
}

\author{
Yvonne Roth, Dickinson State University, Yvonne.Roth@dickinsonstate.edu \\ Deanna Klein, Minot State University, Deanna.Klein@minotstateu.edu
}

\begin{abstract}
Online courses have grown in recent years to meet the needs of a diverse group of adult learners who come from different generations, with most ranging in age from 25 to 50. These adult learners may not be able to enroll in traditional face to face courses because of distance, jobs, families, course scheduling conflicts, or other commitments. They possess unique learning styles and preferences for certain teaching elements. This paper outlines some of these preferred teaching elements and offers recommendations for the online instructor to consider when designing a course in the online environment.
\end{abstract}

Keywords: online courses, adult learners, effective online education

\section{INTRODUCTION}

Online adult learners include individuals of different generations who may not be able to enroll in traditional face to face courses because of circumstances which prevent them from doing so. Some adult learners are already employed and are looking for further education in order to receive a promotion or to change careers. Others may have started a family and find it more convenient to enroll in online courses. Traditional-age students on campus may have course schedule conflicts which require them to enroll in an online course in order to meet graduation requirements on time.

In addition to belonging to diverse age groups, adult learners bring a wide range of computer literacy skills to their virtual classrooms. While some may be comfortable with internet searches, they may never have attached anything to an email. Some may have used Microsoft Word but have never worked with PowerPoint. Some adult learners are completely comfortable in the online environment but may struggle with time management. Each new piece of software or online task can present a challenge for the novice adult learner in an online course.

The challenge for the online instructor is to find teaching strategies which meet the needs of this diverse group of learners. There are a variety of features available in a typical course management system. These may include discussion forums, chat rooms, blogs, video capabilities, recorded lecture, synchronous discussion with or without video, and course email. Simply directing students to these features in an online course does not guarantee student understanding.

Finding the right combination of strategies to encourage student success can mean the difference between retaining the online learner in a successful learning experience and losing students who have not adapted to Web-based instruction. Academic success can be a big factor in determining whether or not students continue to enroll in college courses. Many faculty members and administrators in higher education are concerned with student retention and recognize the need for quality control for all courses in order for students to perform well and achieve the skills they need to succeed.

\section{LITERATURE REVIEW}

Online courses have grown in popularity in the last decade. The National Center for Educational Statistics [2] reported that in 2006-2007, a total of 97\% of public two-year degree-granting institutions offered distance education courses, and $89 \%$ of public four-year degree-granting institutions offered distance education courses. Growth of online courses makes up a large part of this increase, and because of this, many college instructors have been placed 


\section{Issues in Information Systems}

Volume 13, Issue 2, pp. 155-163, 2012

in a position of teaching an online course with no special training other than in the use of the course management system.

\section{Developing an Effective Online Course}

Johnson and Aragon [21] reasoned that the advent of television could have significantly changed education, yet this innovation in technology was used in a traditional way. Television simply provided a "talking head" in keeping with the educational methods in use at the time. Rather than using creativity and innovation, the full potential of the technology was ignored. In the same way, online courses often build on traditional face-to-face teaching practices.

An instructor can't simply convert a traditional course into a Web-based course while ignoring the potential of the technology. An instructor must consider the role of the teacher and learner as well as the design of the online course and the teaching strategies used [11]. Additionally, student interactivity in online courses points to more positive attitudes and higher levels of achievement [15] which would indicate that the online instructor must also find ways to foster interactivity while using the tools available in the online course.

Palloff and Pratt [27] addressed this dilemma in a book that presented the realities of teaching in this dynamic online environment. Durrington, Berryhill, and Swafford [15] summed up the ideas of Palloff and Pratt [27] in this way, "Instructors are faced with the task of developing effective instruction in a context with which they are unfamiliar and teaching in a context that students request but do not prefer" [15].

In spite of these perceivable handicaps, research has shown that with proper use of technology, timely feedback, and interaction between students and instructors, online education can be just as effective as traditional classroom learning [25]. Although Moore and Thompson [25] conducted their research over twenty years ago, they identified the importance of interaction and instructor preparation and planning in order for students to succeed with distance learning. These same elements can contribute to student success in the online environment today $[16,3,6]$.

Recognizing the importance of interactivity, online educators must be comfortable with teaching in the online environment without the help of visual feedback from students [11]. However, instructors who are experienced with the tools of the online teaching environment may not realize how difficult it can be for an adult learner who is approaching a course management system for the first time. Seemingly simple communication tools such as the discussion board, chat room, or course email can be challenging to the novice user [33].

\section{Today's Online Adult Learner}

Because online adult learners fall into different generational groups, an understanding of the traits that may be typical of each generation may assist educators in meeting the educational needs of this diverse group of students. Typical classifications include the following with some variations in the years:

- $\quad$ Traditionalists were born before 1947,

- $\quad$ Baby Boomers were born between 1947 and1965,

- $\quad$ Generation Xers were born between1966 and1980, and

- $\quad$ Generation Y or Millennials were born after 1980 (also called Net Generation or Me Generation).

Traditionalists are not commonly enrolled in online courses. In fact, Kiel [22] stated that less than $25 \%$ of individuals 60 and over own a computer, and of those approximately $11 \%$ actually use the internet.

While this group of individuals is finding it helpful or even necessary to use computers, it is not always easy for them to make this adjustment. Computer courses and software are written for a younger generation who already possess the foundational skills needed to move forward with computer literacy [4]. Older adults may struggle with using the keyboard, moving the cursor with the mouse, and the coordination needed to click the mouse [29]. 


\section{Issues in Information Systems}

Volume 13, Issue 2, pp. 155-163, 2012

While Kiel [22] recognized the existence of a "digital divide," her research proved that Traditionalists could learn to use computers comfortably, and when they did, they felt computers made life easier. However, Kiel's research group used computers mainly for email communication and internet surfing, rather than education.

Most online students are between the ages of 18 and 50 which classify them as Generation Y, Generation X, or Baby Boomers. Each group has certain characteristics which appear specific to that group. However, there are commonalities among adult learners. Adult learners prefer choices and variety in course design [3]. Learning must be relevant and usable and take place in an environment built on collaboration and respect. Adults want to be in control of their learning [9].

Given these common characteristics among adult learners, there are also distinct traits that are more identifiable among certain generations. Twenge [36] summarized these differences like this, "Those born since 1970 have watched 100 channels of television for much of their lives; those born after 1980 have used computers since early childhood, and those born since 1990 barely remember a time when the Internet did not exist."

Regarding the oldest group, Smith and Hunter stated, "Baby Boomers have a love-hate relationship with technology" [32]. Most do what they are asked to do without questioning the reason behind why they are learning something [36]. This group values competition, change, hard work, success, and teamwork [23]. Baby Boomers seek praise and recognition and are achievement oriented [14].

Not surprisingly, the children of these Baby Boomers, or Generation Xers, have a strong sense of independence. They value information, feedback, and communication [23]. Generation Xers grew up with technology and the information and power that come with it [31]. Technology is not only used on the job but also for shopping, communication, and entertainment.

Some of the traits of Generation X can be seen in their children who are known as Generation Y or Millennials. Millennials are well-adapted to technology and comfortable with multitasking [7]. Millennials are team players who expect a structured work environment with instant access to information [31]. However, they also expect flexible working conditions that are designed to fit their lifestyles [7]. Millennials are quick to learn something new and benefit from mentoring and personal attention [31]. This group is most likely to be comfortable with diversity since they have had the most exposure to different lifestyles and cultures [7].

Tapscott [35] has identified a portion of this group as the Net Generation or N-Gen. According to Tapscott [35], the N-Gen was born between 1977 and 1997. In reference to the computer savvy of this generation, Tapscott [35] stated, "For the first time in history, children are more comfortable, knowledgeable, and literate than their parents about an innovation central to society."

Adams [1] is a Generation X teacher who has used several different Google applications to meet the needs of the NGeneration student. Among these are Google Search, Gmail, Google Groups, GTalk, Google Calendar, Google Docs, and iGoogle. Adams emphasized the use of these tools to "research smarter rather than harder." By mentoring a Baby Boomer colleague of his in the use of these applications, Adams suggested that it is possible to address the digital divide between age groups, specifically Baby Boomer and Generation X teachers and their twenty-first century students, and socioeconomic groups, "the haves and have nots."

Twenge [36] has determined that the Net Generation or Me Generation exhibits more narcissistic behavior which in turn leads to a sense of entitlement. Twenge observed that because of their sense of entitlement, "Arguing over grades will be more common and will take more creative forms, such as asking for extra credit after the class is over." He also stated that more of these students expect to make up missed exams or receive at least a B just for coming to class.

Another reason for this sense of entitlement according to Twenge [36] is the fact that this generation has received more A grades for doing less work. In 1976, 18\% of students claimed to have an A average compared to $33 \%$ of 


\section{Issues in Information Systems}

Volume 13, Issue 2, pp. 155-163, 2012

students in 2006. This is an $83 \%$ increase in the number of students claiming to have received A grades, yet the amount of hours spent on homework had decreased from 1976 to 2006, with some students reporting they did no homework at all.

Twenge [36] suggested that this generation will do better with a well-structured course environment and precise instructions. With increased reliance on clear rules and requirements, a syllabus becomes a critical online course document for this generation.

Twenge [36] noted that "fewer and fewer young people read books, which suggests a decline in the skills involved in reading long passages of text." Young people are accustomed to reading emails, short passages on web pages, and text messages. This means there is less of a chance that a course textbook will be read by these students. Publishers are responding to this by writing shorter textbooks and chunking material in smaller segments.

Generation Me prefers hands on activities to lecture and prefers visual aids such as pictures and video segments [36]. In the online environment, technology allows instructors to incorporate these elements. Twenge [36] recommends "breaking lectures into short chunks, using video and promoting hands-on learning" while keeping content and learning standards at the same level.

Regardless of the generational group to which a particular adult learner belongs, Ausburn [3] offered this advice, "It is important to understand their preferences for various aspects and features of online learning and to apply this understanding to online course design and delivery." It is also important for instructors to keep in mind that while many students choose online courses, they may actually prefer face to face instruction and interaction with others [5].

\section{Effective Feedback}

Research points to the importance of communication and feedback in the online course environment $[20,34,17]$. Bonnel [8] asserted that "feedback from faculty can be a way to keep students engaged and help them gain skill proficiency and apply concepts in diverse contexts." She even went so far as to state that students in the online environment could feel abandoned without feedback, and this could lead to procrastination or failure of the course. Gaytan and McEwen [16] contended that feedback "...must be meaningful, timely, and should be supported by a well-designed rubric when possible."

In a study completed by Holmes and Smith [19], students expressed their opinions with regard to grading practices in online classes. The most frequent complaint was too little feedback or no feedback at all. The second most frequent complaint was that most of the feedback received was negative.

The issues relating to feedback may be due to a lack of faculty training in grading online assignments. Jennings and McCuller [20] emphasized that "grading of written assignments submitted in an online environment provides a time consuming challenge to those responsible for marking and grading the work." However, they offer several alternatives to the traditional red pen, including inserting comments in word processing software such as Microsoft Word, using comment boxes in Adobe Acrobat, purchasing grading software such as Markin, or using the features of a Tablet PC. Gray [17] suggested that email could be used in place of face to face feedback or tutorials. For more immediate feedback, he recommended a chatroom for synchronous conferencing but also advised that a phone conversation could be used to provide effective feedback as well.

As Holmes and Smith [19] noted, though, in addition to the method of feedback used, timeliness and quality of feedback are also important considerations. A 2003 study completed by Holmes and Smith showed that students expect more feedback and more positive comments from instructors. They want to know how they can improve on future assignments. Students who participated in the study recommended that faculty provide clearly communicated objectives and use rubrics to promote consistency and fairness in grading. Timeliness of feedback was also cited as a student concern. 


\section{Issues in Information Systems}

Volume 13, Issue 2, pp. 155-163, 2012

In a similar study completed by Steinweg [34], surveys were mailed to students in an online graduate class with a mean age of 35.5. All students surveyed stated they liked receiving feedback other than a numerical grade. Students further indicated they liked feedback typed directly on the assignment or in the form of an email. Of the students surveyed, 58\% expressed that handwritten feedback added a "personal touch." Only 5\% preferred feedback by phone [34].

\section{Instructor Communication in the Online Environment}

With regard to this "personal touch," Aragon [2] asserted that social presence is a key element for student learning. Social presence can be viewed as the degree to which a person feels a sense of connectivity or comfort with a particular group. This interaction can be lacking if instructors do not have the skills to promote collaboration in the online environment [5]. The challenge for the instructor then is to create a learning community where students feel connected to each other and the instructor and comfortable in the course environment [2].

Beard \& Harper [5] referred to teaching without the physical presence of a teacher in the classroom as a "modern day miracle." This emphasizes the importance of other means of communication in order for students to achieve. Aragon [2] offered several suggestions to create social presence, including welcome messages, student profiles, use of audio, small class sizes, and group projects. He further suggested that instructors participate in discussion forums, provide timely responses to emails, give frequent feedback, initiate conversations with students, share personal stories and experiences, and use humor and emoticons. He also believed that students could use these same elements to foster social presence in the online environment.

Ausburn [3] used a questionnaire that allowed students in online courses to rank eight different online course features. When the features were analyzed, Ausburn was able to identify four distinct tiers based on students' rankings. Communication from the instructor in the form of announcements and reminders, the syllabus and course information, and the assignment instructions were in the top tier rated by students as most important. Not surprisingly, all of these elements provide the structure and guidance that online students need to stay focused and succeed in the online environment.

\section{Interaction in the Online Environment}

Steinweg, Williams, and Warren [34] referred to the connectivity and personal interaction in online classes as "reaching through the screen." They suggested that improving feedback and providing a "human touch" can help to address student concerns and increase social presence. Durrington, Berryhill, and Swafford [15] agreed that interactivity within an online course results in higher student performance, more positive attitudes, and an increased chance of student success. They stated that timeliness in responding to student concerns is one way to create an interactive learning environment. Even something as simple as using students' names or emoticons when responding helps to give a course a more personal feel.

Social networking technologies can also provide the means to create learning communities in online classes [10]. Burgess recommends social networks such as LinkedIn or Facebook to assist students, especially women, with increasing their social connections. LinkedIn can connect students to professionals within their future career area or interest group. Burgess also suggests the use of discussion posts in online blogs to give students an expanded perspective of issues in the curriculum. According to Burgess, the goal of social networking is to build relationships that extend beyond the virtual classroom and provide a foundation for professional connections that last into the future.

Many online instructors turn to the discussion board for course interaction. Gray [17] commented that written communication is the foundation of most interaction in an online class, and the discussion board gives students the medium to communicate in a virtual classroom setting. Gray recommended that in this informal discussion environment, an instructor expect good writing skills but focus more on thinking skills when grading discussion 


\section{Issues in Information Systems}

Volume 13, Issue 2, pp. 155-163, 2012

posts and course communication. More rigorous grading of grammar and writing skills could be saved for "formal assignments and projects."

Requiring students to reply to a certain number of discussion posts and providing expectations for the quality of the post also support interactivity in the discussion forum. Instructor questions based on student posts encourage more critical thinking with regard to the topic. This can also be followed up with a private email to the student commenting on the value of his or her post [15].

\section{Learning Communities and Group Projects}

Certain elements of a learning community surface in a typical discussion forum. For example, students begin to share experiences and look at issues from different perspectives. Leaders may evolve who provide written support for the ideas of other students. By taking the initiative in replying to classmates, these leaders promote further discussion. Others may prefer to keep their posts more concise and simply answer the question posed [18]. Guldberg [18] reasoned that discussion forums can be used "to empower people to become active agents in their own learning and to help them develop as thinkers."

Some instructors prefer to further empower students by allowing them to choose the discussion topics based on the course content and then facilitate the discussion for the week. Topics can be assigned individually or to small groups. Students can even be charged with creating the rubric used to evaluate the discussion posts [15].

Collaborative group activities such as case study problems or other problem-based learning scenarios can foster student interactivity. Students use course email, discussion posts, or chat to determine who is responsible for each task and how the findings will be presented. This gives students a chance to get to know each other and develop camaraderie. They also learn the importance of teamwork in creating the final product [15].

\section{Online Course Content}

One way for instructors to provide content is through the use of PowerPoint ${ }^{\circledR}$ presentations. Shank [30] recommended adding narration to give more meaning to the text and graphics on a PowerPoint ${ }^{\circledR}$ slide. According to Shank, such narration should be written for hearing, rather than reading, for full effectiveness since this takes the place of a lecture in an online course.

Pugsley [28] pointed out that PowerPoint ${ }^{\circledR}$ presentations allow learners "opportunities to see different imagery and integrate new information with existing knowledge." PowerPoint ${ }^{\circledR}$ presentations also allow instructors to incorporate visual elements such as photos and videos.

Adding videos or video lectures can enhance the online learning experience as well. Some sophisticated recording software allows for indexing of course lecture content which enables a student to quickly advance to a particular topic in the recorded lecture. Another popular feature is the ability to search by keyword for a specific lecture topic.

A 2003 study completed by Cramer, Collins, Snider, and Fawcett [13] demonstrated that recorded lectures which made use of multimedia presentations and audio lectures contributed to higher overall grades. Students had the opportunity to review video lectures to improve understanding of course material. For those who made use of the recorded lecturers, test scores were higher than those who opted not to watch the video lectures.

Merrill, Reinckens, Yarborough, and Robinson [24] noted similar results pertaining to recorded lectures with over half of the students surveyed stating that recorded lectures improved student learning. They further noted that with the recorded lectures, learning had shifted from an instructor-centered approach to a student-centered approach which led to greater student satisfaction. 


\section{Issues in Information Systems}

Volume 13, Issue 2, pp. 155-163, 2012

\section{Assessment}

Whether an instructor chooses to use group projects, discussion posts, papers, or case study analysis, at some point it is necessary to create assessment tools to measure student understanding of course objectives. Gaytan and McEwen [16] claimed that effective assessment is a key element in online learning. Online assessment provides many advantages such as immediate feedback, electronic gradebook entries, student-centered learning, and accuracy.

In a 2007 study of online students completed by Gaytan and McEwen [16] 73\% of students responded that assessments were used to evaluate student work. Over half of all students surveyed stated that instructors used a variety of assessment tools including portfolios, projects, and simulations. Gaytan and McEwen believed that in addition to a variety of formal assessments, students can also benefit from peer assessment. They further emphasized the importance of evaluating emails, chats, and discussion posts to gauge student understanding.

It is evident that there are many tools available for an instructor to use in the online environment. Cooper [12] summarized the effectiveness of these online learning elements in this way, “...with the right subject matter, with the right instructor or facilitator, and for the right student, Internet or online classes can provide an effective educational environment and offer a viable alternative to traditional classroom instruction." The goal of both online instructors and face to face instructors is the same-providing an engaging, interactive learning environment for students. The online instructor simply has to master different tools and techniques.

\section{CONCLUSIONS}

Research points to the importance of feedback and communication in the online course environment $[20,34,17]$. Bonnel [8] states that students in the online environment could feel abandoned without feedback which could lead to procrastination or failure of the course.

Group projects were selected as the least effective teaching element. This could be attributed to communication challenges. Communication is essential for effective online collaboration, and many students may not be comfortable enough in the course environment to conduct the conversation needed to develop a group project online. Without strong student interaction, the task of completing a group project may seem daunting. Other challenges include changes in the class roster that necessitate reorganization of groups and unequal participation by all group members. It is understandable that students would become frustrated when other members of the group do not participate, especially when grades depend on group participation.

While some students may not see the value of completing group projects in the online course environment, research shows that this interaction gives students a chance to get to know each other and to develop camaraderie which can help students to feel connected and comfortable in the online environment. Students also learn the importance of teamwork in creating the final product [15]. Student interaction fosters social presence which can increase the chance of student success [2]. Thus it is important for instructors to become skilled in promoting interaction and connectivity among students. Group projects should be assigned to allow students opportunities to develop the skills needed to collaborate as part of a team.

Differences in most effective teaching elements do seem to exist among different generations. These differences are consistent with available research but further study is needed to determine the reasons for the generational differences.

\section{RECOMMENDATIONS}

Quality control of online courses should be a high priority within each university. Online faculty could benefit from training designed to help them recognize differences in learning styles in students of different generations and to guide faculty in using a variety of teaching styles to meet the needs of individual students. Also, it is important for faculty members to identify strengths and weaknesses in their own technology usage in order to address areas where 


\section{Issues in Information Systems}

Volume 13, Issue 2, pp. 155-163, 2012

training may be needed. The importance of timely communication and feedback should be emphasized in faculty training, and guidance should be provided in these areas if necessary. Students need interaction with the instructor in order to feel a connection to the class and to increase the chances for success in the course. A conscious effort should be made by faculty to provide timely responses to student questions and to give constructive feedback in addition to number or letter grades. Serious consideration should be given to online course evaluations, and corrective action should be taken whenever feedback and communication are inadequate.

Online courses can be effective in helping students to achieve program and course outcomes. Their effectiveness can be improved by preparing faculty to engage students in a variety of learning activities in a rich course environment with timely communication and feedback.

\section{REFERENCES}

1. Adams, D. (2008). Gaga for Google in the twenty-first century advanced placement language classroom. Clearing House, 82(2), 96-100.

2. Aragon, S. R. (2003). Creating social presence in online environments. New Directions for Adult \& Continuing Education, (100), 57-68.

3. Ausburn, L. (2004). Course design elements most valued by adult learners in blended online education environments: An American perspective. Educational Media International, 41(4), 327-337. doi:10.1080/0952398042000314820.

4. Bean, C., \& Laven, M. (2003). Adapting to seniors: Computer training for older adults. Florida Libraries, 46(2), 5-7.

5. Beard, L. A., \& Harper, C. (2002). Student perceptions of online versus on campus instruction. Education, $122(4), 658$.

6. Beffa-Negrini, P., Cohen, N., \& Miller, B. (2002). Strategies to motivate students in online learning environments. Journal of Nutrition Education \& Behavior, 34(6), 334.

7. Bell, N. \& Narz, M. (2007). Meeting the challenges of age diversity in the workplace. The CPA Journal Online. Retrieved from http://www.nysscpa.org/cpajournal/2007/207/essentials/p56.htm.

8. Bonnel, W. (2008). Improving feedback to students in online courses. Nursing Education Perspectives, 29(5), 290-294.

9. Boulmetis, J. (1999). Characteristics of adults as learners are not culturally defined. Adult Learning, 11(1), 2.

10. Burgess, K. R. (2009). Social networking technologies as vehicles of support for women in learning communities. New Directions for Adult \& Continuing Education, (122), 63-71. doi:10.1002/ace.335.

11. Conceição, S. (2007). Understanding the environment for online teaching. New Directions for Adult \& Continuing Education, (113), 5-11. doi:10.1002/ace.242.

12. Cooper, L. W. (2001). A comparison of online and traditional computer applications classes. T H E Journal, $28(8), 52$.

13. Cramer, K. M., Collins, K. R., Snider, D., \& Fawcett, G. (2006). Virtual Lecture Hall For In-Class And Online Sections: A Comparison Of Utilization, Perceptions, And Benefits. Journal of Research on Technology in Education, 38(4), 371-381.

14. Dols, J., Landrum, P., \& Wieck, K. (2010). Leading and managing an intergenerational workforce. Creative Nursing, 16(2), 68-74. doi:10.1891/1078-4535.16.2.68.

15. Durrington, V., Berryhill, A., \& Swafford, J. (2006). Strategies for enhancing student interactivity in an online environment. College Teaching, 54(1), 190-193.

16. Gaytan, J., \& McEwen, B. (2007). Effective online instructional and assessment strategies. American Journal of Distance Education, 21(3), 117-132. doi:10.1080/08923640701341653.

17. Gray, R. (2002). Assessing students' written projects. New Directions for Teaching \& Learning, (91), 37.

18. Guldberg, K. (2008). Adult learners and professional development: peer-to-peer learning in a networked community. International Journal of Lifelong Education, 27(1), 35-49. doi:10.1080/02601370701803591.

19. Holmes, L. E., \& Smith, L. J. (2003). Student evaluations of faculty grading methods. Journal of Education for Business, 78(6), 318-323. 


\section{Issues in Information Systems}

Volume 13, Issue 2, pp. 155-163, 2012

20. Jennings, S. E., \& McCuller, M. Z. (2004). Meeting the challenges of grading online business communication assignments. Paper presented at the $69^{\text {th }}$ Annual Convention: Association for Business Communication, Cambridge, Massachusetts. Retrieved from http://www.businesscommunication.org/conventionsNew/ProceedingsNew/2004New/PDFs/02ABC04.PDF.

21. Johnson, S. D., \& Aragon, S. R. (2003). An instructional strategy framework for online learning environments. New Directions for Adult \& Continuing Education, (100), 31-43.

22. Kiel, J. (2005). The digital divide: Internet and e-mail use by the elderly. Medical Informatics and the Internet in Medicine, 30(1), 19-23.

23. Mask, D. (2007). Managing the generation mix in the workplace: Tips to manage the generation gap. Retrieved from http://searchwarp.com/swa151634.htm.

24. Merrill, E. B., Reinckens, T., Yarborough, M., \& Robinson, V. (2006). Retaining and assisting nontraditional nursing students in a baccalaureate nursing program utilizing Blackboard \& Tegrity technologies. $A B N F$ Journal, 17(3), 107-110.

25. Moore, M. G., \& Thompson, M. M. (1990). The effects of distance learning: A summary of literature (Research Monograph no. 2). University Park, PA: American Center for the Study of Distance Education.

26. National Center for Education Statistics (NCES). (2008). Distance education at degree-granting post-secondary institutions: 2006-07. U.S. Department of Education. Retrieved from http://nces.ed.gov/fastfacts/display.asp?id=80.

27. Palloff, R. M., and Pratt, K. (2001). Lessons from the cyberspace classroom: The realities of online teaching. San Francisco: Jossey-Bass.

28. Pugsley, L. (2010). Design an effective PowerPoint presentation. Education for Primary Care, 21(1), 51-53.

29. Seals, C., Clanton, K., Agarwal, R., Doswell, F., \& Thomas, C. (2008). Lifelong learning: Becoming computer savvy at a later age. Educational Gerontology, 34(12), 1055-1069. doi:10.1080/03601270802290185.

30. Shank, P. (2011). Making Online PowerPoint Content Engaging: Writing a Narration Script. Online Classroom, 4-5.

31. Simons, N. (2010). Leveraging generational work styles to meet business objectives. Information Management (15352897), 44(1), 28-33.

32. Smith, R., \& Hunter, B. (2007). Baby Boomers and Generation X: Nursing education beyond the computer. Oncology Nursing Forum, 34(2), 572.

33. Stein, D., Wanstreet, C., \& Calvin, J. (2009). How a novice adult online learner experiences transactional distance. Quarterly Review of Distance Education, 10(3), 305-311.

34. Steinweg, S., Williams, S., \& Warren, S. (2006). Reaching through the screen: Using a Tablet PC to provide feedback in online classes. Rural Special Education Quarterly, 25(2), 8-12.

35. Tapscott, D. (1998). Growing up digital. The rise of the Net Generation. New York: McGraw Hill.

36. Twenge, J. (2009). Generational changes and their impact in the classroom: Teaching Generation Me. Medical Education, 43(5), 398-405. doi:10.1111/j.1365-2923.2009.03310.x. 